\title{
Influence of yaw on propeller aerodynamic characteristics
}

\author{
Van Bang Nguyen ${ }^{1,}$, Dalibor Rozehnal ${ }^{1}$, Jakub Hnidka ${ }^{1}$, and $V u$ Uy Pham $^{2}$ \\ ${ }^{1}$ University of Defence, Kounicova 65, 66210, Brno, Czech Republic \\ ${ }^{2}$ Military Technical Academy, Hoang Quoc Viet 236, Hanoi, Vietnam
}

\begin{abstract}
Between the propeller axis and free stream direction, it can still be a non-zero yaw angle. This paper introduces some propeller experiments, in which the propeller aerodynamic characteristics have been determined in various yaw angle and different rotational speeds. The experimental aerodynamic characteristics are acquired dynamic values, from which the influence of yaw conditions on the frequency and the amplitude of propeller thrust and torque can be obtained.
\end{abstract}

\section{Introduction}

The research of air propeller assumes that the axis of the propeller disc is aligned with inflow direction [1]. However, between the propeller axis and airflow direction can still be a non-zero angle, when the propeller aircraft is in some special flight regimes as climbing, flying horizontally at low speed, fighter maneuvers or flying after an engine failure in multiengine propeller aircraft [2], [3]. The small multicopters (rotorcraft with more than one main rotor) operate usually in the similar conditions (Fig. 1.), because all their rotors spend most of its flight time in yaw flow at the same yaw angle $\theta$.

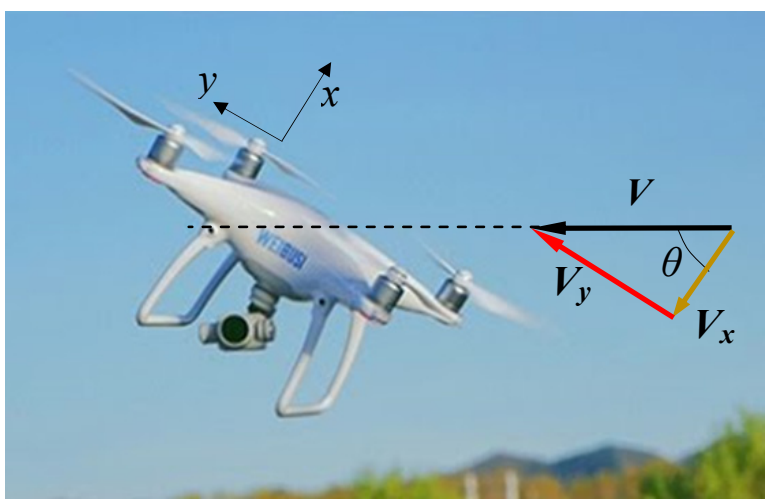

Fig. 1. The kinetic scheme of the propeller in yaw [4].

This report aims to determine the influence of yaw conditions (yaw angle and rotational speed) on the frequency and the amplitude of dynamic component of propeller thrust and torque using experimental results from simple wind tunnel experiment. The propeller has been measured at the various yaw angle from $0^{\circ}$ to $90^{\circ}$ (with constant rotational speed) and various rotational speeds (with constant yaw angle $45^{\circ}$ ).

\section{Experiment setup}

\section{Propeller and wind tunnel}

The two-blade fixed pitch propeller Bambula $18 \times 8$ with a diameter of 18 inches was used in this experiment. The test bench is optimized to measure the dynamic components of both force (thrust) and moment (torque) of propeller shaft, at various yaw angles and rotational speeds.

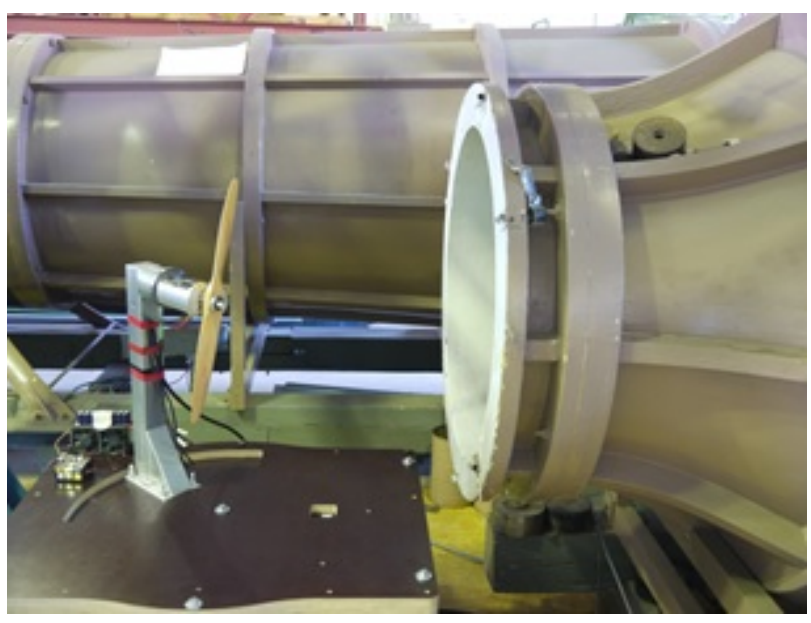

Fig. 2. Propeller setup in yaw.

The placement of test bench in the wind tunnel, which is located in a wind tunnel of the University of Defence in Brno (Fig. 2). It is the low-speed return-flow wind tunnel with an open test section. At the core of the wind tunnel is a $500 \mathrm{~mm}$ diameter wooden propeller fan driven by an $18000 \mathrm{~W}$ electric motor [4]. The free stream speed V in the test section is constant at $V=12 \mathrm{~m} \cdot \mathrm{s}^{-1}$. The yaw mechanism allows changing the yaw angle from $0^{\circ}$ to $90^{\circ}$ with step of yaw angle $5^{\circ}$. 


\section{Sensor and data acquisition}

The test bench implements a piezoelectric 2-component transducer Kistler 9365B, which reacts very quickly to all changes of measured parameters. That means that the results obtain thrust or torque pulsation, if they occur. The NI DAQ hardware and an interface programmed in LabVIEW software have been prepared for the data acquisition

The thrust of the propeller can be measured in range from $-20 \mathrm{kN}$ to $20 \mathrm{kN}$, and the range of torque is from $200 \mathrm{Nm}$ to $200 \mathrm{Nm}$. It is important to note that despite the significant range of the sensor, it can measure forces with precision and it has a resolution of $3,6 \mathrm{pC} / \mathrm{N}$ and of $140 \mathrm{pC} / \mathrm{Nm}$. .

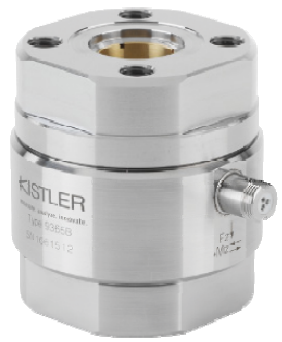

Fig. 3. The 2-component piezo sensor Kistler 9365B

The experimental data are compared only in a constant time $0.2 \mathrm{~s}$. In this time section, only the change of measuring parameters is acquired and the average value of their parameters in this time is always setup to zero.

\section{Repeat of measurements}

In the first series of measurements, the rotational speed $n$ of the propeller in each repeating cycle of measurement remained nearly constant at about $n=5400 \mathrm{rpm}$ and the yaw angle changes from $0^{\circ}$ to $90^{\circ}$ with step of $15^{\circ}$. The aim of this first experiment is to identify the influence of yaw angle on thrust and torque characteristics and its frequency analysis performed via fast Fourier transform (FFT).

In the second series of measurements, the rotational speed $n$ changes from $2200 \mathrm{rpm}$ to $5380 \mathrm{rpm}$, while the yaw angle is constant at $45^{\circ}$. The aim of this experiment is to identify the influence of rotational speed $\mathrm{n}$ on thrust characteristics of propeller.

\section{Results and discussion}

The theoretical frequency $f_{o}$ can be estimated by using equation (1). During one revolution of the propeller rotor in yaw condition, every blade section operate an oscillation [5], [6]. The angle of attack (AoA) of blade section is changed from $\alpha_{\min }$ to $\alpha_{\max }$ and later returns to the minimum value with a frequency [5]. This periodical change of every blade section also results to characteristics of propeller periodical oscillation. The theoretical frequency $f_{o}$ of oscillation generated by the change of AoA of blade section can be calculated by the expression:

$$
f_{0}=k \frac{n}{60}
$$

The value of frequency $f_{o}$ of the first experiments $(k=2$, $n=5400 \mathrm{rpm}$ ) according to (1) must be around $180 \mathrm{~Hz}$.

\subsection{Influence of yaw on thrust}

Fig. 4 shows the thrust oscillation in time domain and sdomain. The thrust generated by propeller in case of non-zero yaw angle alters around average value and appears to perform nearly periodical oscillation.
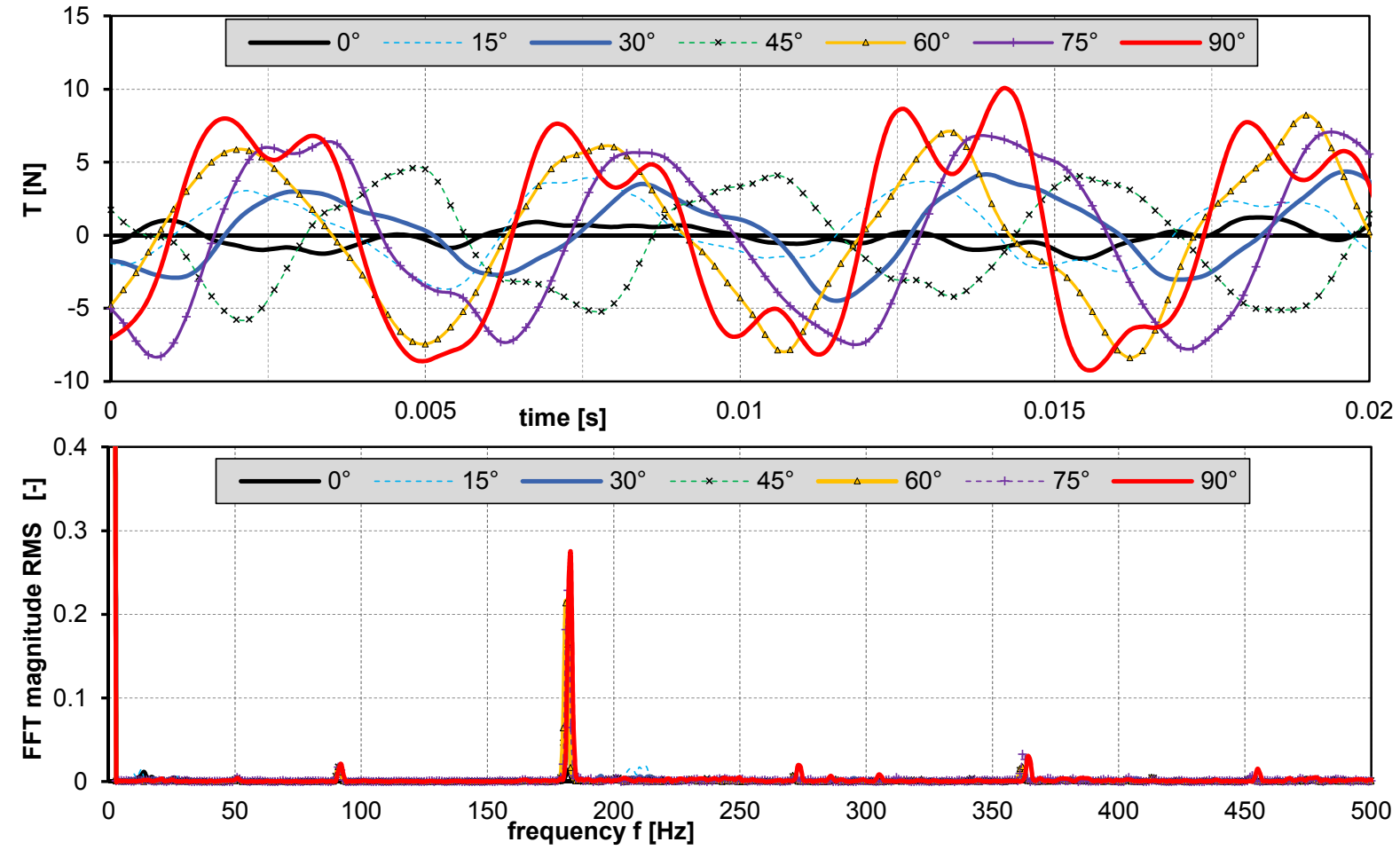

Fig. 4. Thrust - time curves and its FFT for different yaw angles 
The frequency analysis is coincided with the estimation, because the main frequency occurred in every yaw angle is always near with the calculated frequency $f_{o}=180 \mathrm{~Hz}$. Smaller peaks occur around values $90 \mathrm{~Hz}\left(1 / 2 f_{o}\right), 270 \mathrm{~Hz}$ $\left(3 / 2 f_{o}\right)$, and $360 \mathrm{~Hz}\left(2 f_{o}\right)$.

\subsection{Influence of yaw on torque}

The main frequency of torque in every yaw angle is also close to the calculated frequency $f_{o}=180 \mathrm{~Hz}$. The next most common frequency is $360 \mathrm{~Hz}\left(2 f_{o}\right)$.
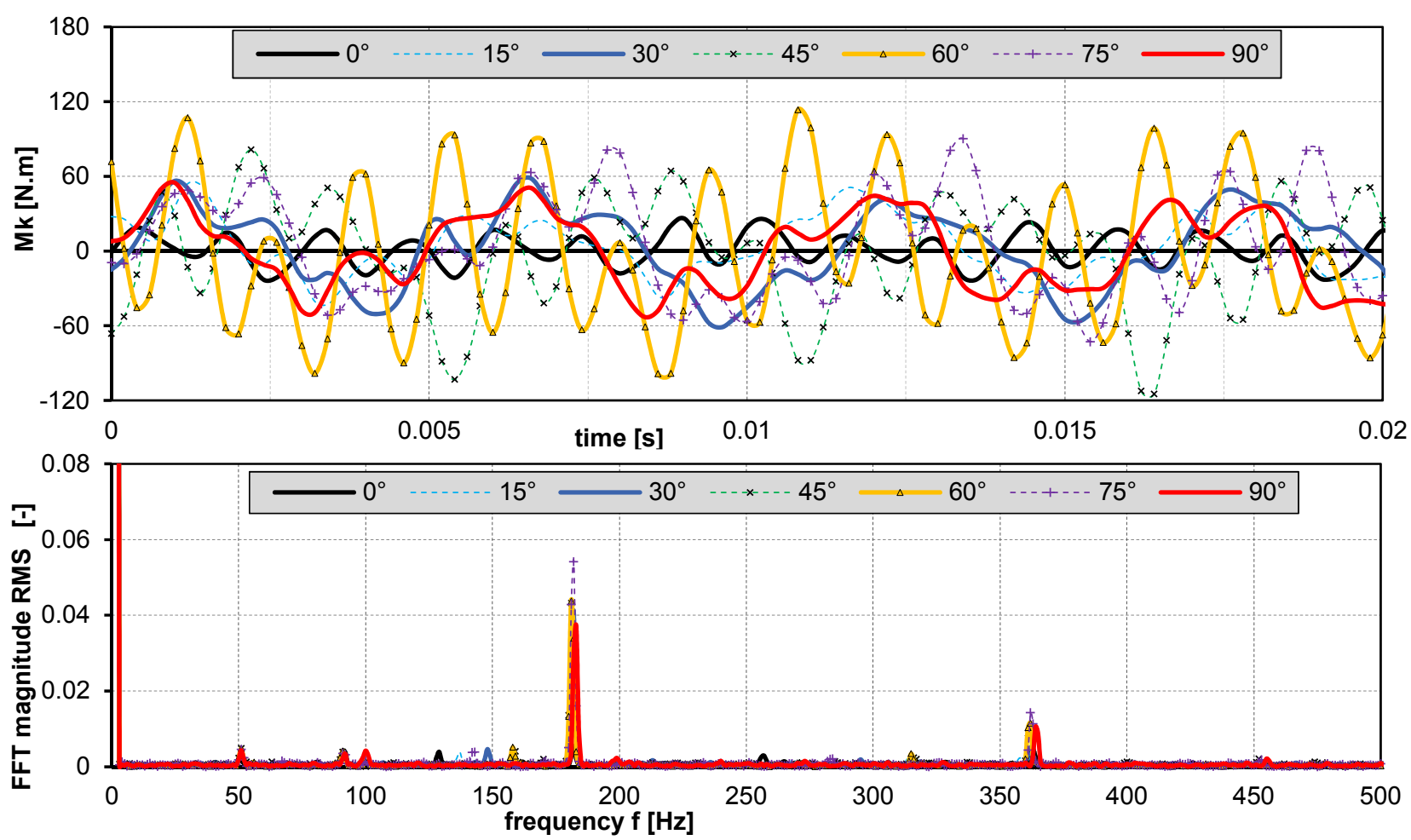

Fig. 5. Torque - time curves and its FFT for different yaw angles, V=12 m.s ${ }^{-1}, \mathrm{n}=5400 \mathrm{rpm}$

There are some frequencies, which occur without any rules. They can be caused by the construction of electric motor, in which the movement of rotor depends on specific number of slots and number of poles.

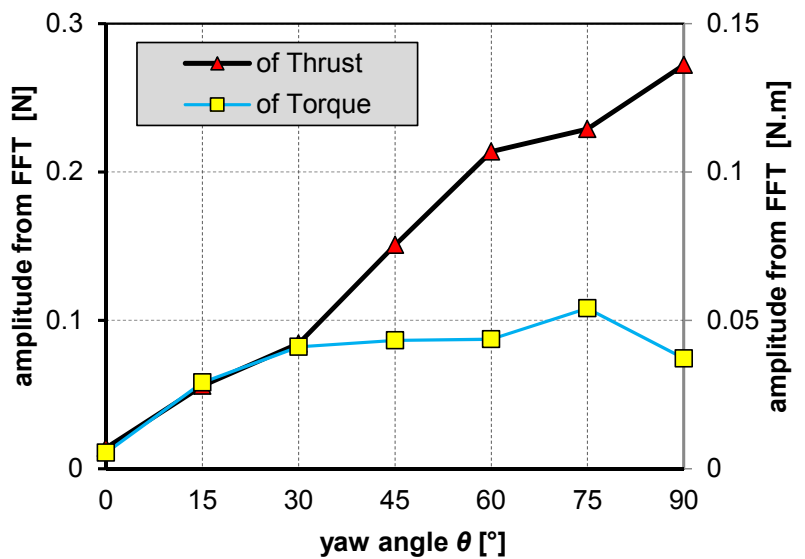

Fig. 6. Influence of yaw on amplitude of dynamic components
Fig. 6. shows the influence of yaw angle on magnitude of amplitude in frequency analysis. It also points out that the magnitude of amplitude of thrust oscillation is significantly depended on yaw angle while it is not for the torque. The magnitude of torque oscillation increases with yaw angle only in range from $0^{\circ}$ to $75^{\circ}$, and then it conversely decreases according to yaw angle. The torque achieves maximum values for yaw angle around $75^{\circ}$.

\subsection{The influence of rotation speed}

This next experiment identifies the influence of rotational speed to thrust characteristics and its frequency analysis. The freestream speed $V$ in the test section in this experiment is $12 \mathrm{~m} \cdot \mathrm{s}^{-1}$ and the rotational speed $\mathrm{n}$ changes from $2200 \mathrm{rpm}$ to $5380 \mathrm{rpm}$, while the yaw angle is constant at $45^{\circ}$. 


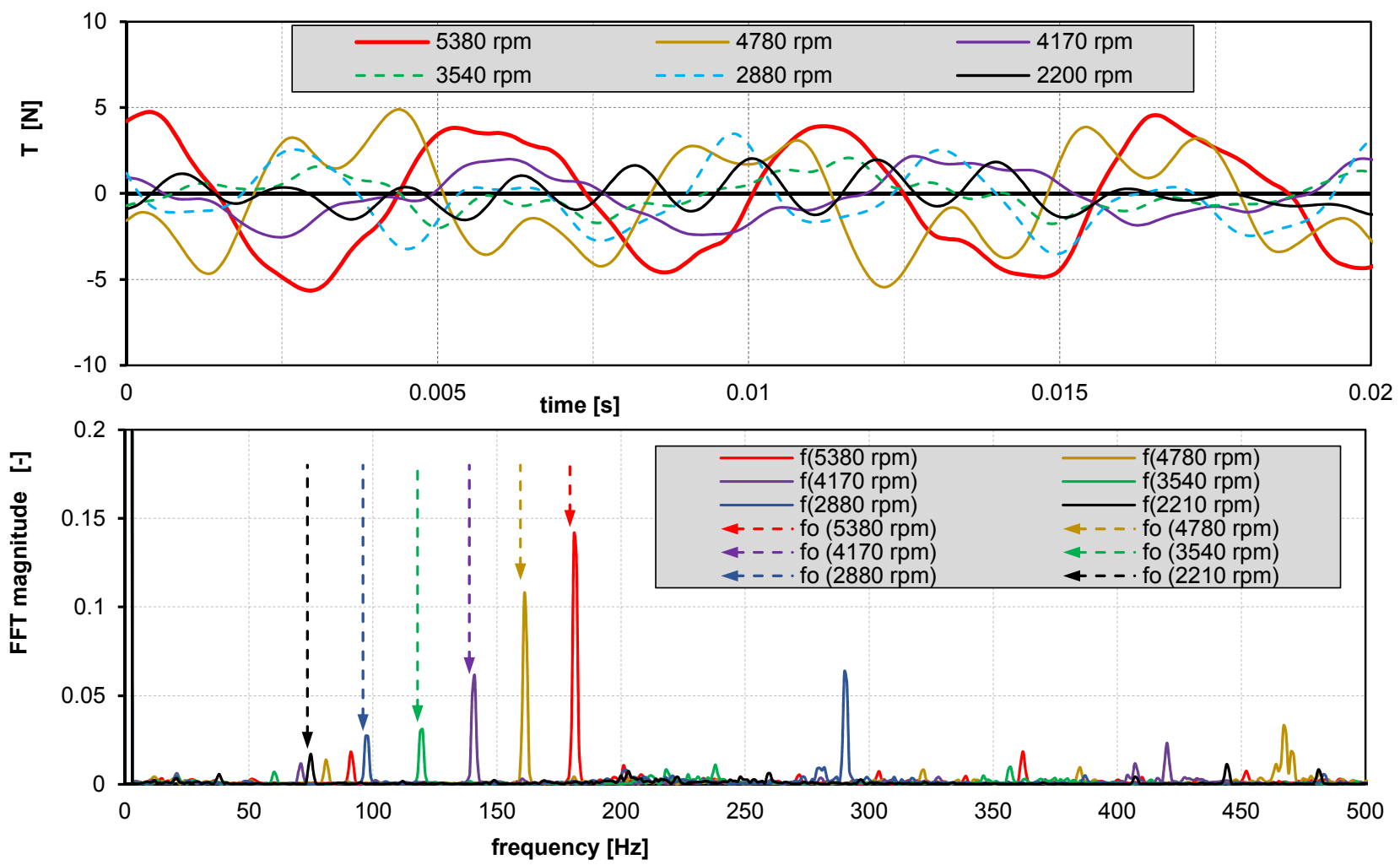

Fig. 7. Thrust - time curves and its FFT for different rotational velocities

The magnitude of thrust oscillation increases proportionally with increasing of rotational speed. The frequency analysis in Fig. 7. shows all peaks and the calculated frequency $f_{o}$ for every yaw condition. The FFT of measured thrust in every rotational speed $n$ always shows one peak coincided with the frequency $f_{o}$ calculated for the corresponding $\mathrm{n}$ by expression (1).

\section{Conclusion}

The experimental results show in which frequencies the thrust or torque pulsation occur and how its amplitude change according to yaw condition.

- The main frequency find from FFT were always near with the calculated frequency $f_{o}$ (Fig. 4., Fig. 5., Fig. 7.).

- The magnitude of thrust oscillation increased clearly proportionally with yaw angle (Fig. 6.).

- The magnitude of torque oscillation increased with yaw angle in range from $0^{\circ}$ to $75^{\circ}$, and then it conversely decreases (Fig. 6.).

- The magnitude of thrust oscillation increases nearly parabolic with increasing of rotational speed (Fig. 7.).

The information about dynamic component of propeller aerodynamic characteristic in yaw can be used to verify the theoretical calculation [7].

\section{References}

1. T. Theodorsen, The theory of propellers. Washington: U. S. Govt. Print. Off (1945).

2. H. S. Ribner, Propellers in yaw. NACA report No. 820 (1945).

3. H. B. Freeman, The effect of small angles of Yaw and Pitch on the characteristics of airplane propellers. NACA report No. 389, (1932). A.

4. D. Rozehnal, Rozvoj experimentální aerodynamiky na UO. Habilitation thesis, University of defense in Brno (2009).

5. N. V. Bang, D. Rozehnal, Aerodynamic hysteresis of oscillating airfoil. In: 23rd International Conference Engineering Mechanics 2017. Brno: Brno University of Technology, Faculty of Mechanical Engineering, Institute of Solid Mechanics, Mechatronics and Biomechanics, Brno, 2017, s. 106-109. ISSN 1805-8248. ISBN 978-80-214-54972, (2017).

6. N. V. Bang, D. Rozehnal, Measurement of Aircraft Propeller in Yaw Flow. In: International Conference on Military Technologies. ICMT: University of defence in Brno, 2017, p. 566-569. ISBN 978-15386-1988-9, (2017).

7. J. Sveda, J. Salga, B. Horeni, Výpočet aerodynamických charakteristik šikmo ofukované vrtule. In: Report VAAZ/635, Brno (1977).

\footnotetext{
* Corresponding author: vanbang.nguyen@unob.cz
} 